\title{
GAMBARAN PENGGUNAAN FINANCIAL TECHNOLOGY (FINTECH) DALAM BENTUK PINJAMAN ONLINE (PINJOL) PADA UMKM DI INDONESIA
}

\author{
I Made Indra $\mathbf{P}^{\mathbf{1}}$, Fanny Novika ${ }^{2}$, Antonius Anton Lie ${ }^{3}$, Insri Nuryati ${ }^{4}$ \\ ${ }^{1,2,3,4}$ Sekolah Tinggi Manajemen Asuransi Trisakti \\ *indraimade1@gmail.com
}

\begin{abstract}
ABSTRAK
Pemanfaatan kemajuan teknologi dalam bidang keuangan semakin berkembang pesat. Inovasi teknologi mendatangkan proses transaksi keuangan yang lebih praktis, salah satunya diaplikasikan pada pinjaman online. Praktik bisnis pinjaman online menghubungkan pemberi pinjaman dengan peminjam secara online. Penyaluran kredit sebanyak 22 triliun dari 99 perusahaan pinjaman online yang terdaftar di OJK telah melakukan 9 juta transaksi pada lebih dari 3 juta masyarakat Indonesia. Perlu dianalisisnya faktorfaktor yang mempengaruhi ketertarikan penggunaan financial technology dalam bentuk pinjaman online. Sebagai salah satu penggerak keuangan Indonesia, UMKM mempunyai peran dalam bertransaksi menggunakan platform pinjaman online. Penelitian ini menggunakan pendekatan kuantitatif dengan melakukana survei online pada UMKM untuk mendapatkan data primer. Hasil survei menunjukkan bahwa 44,41\% UMKM menggunakan pinkol terdaftar, $18,75 \%$ menggunakan pinjol tidak terdaftar dan 36,84\% tidak menggunakan. Usaha yang paling banyak adalah jenis UMKM di bidang kuliner dengan 58,88\% merupakan pekerjaan utama, 50.99\% berpendidikan SMA dan $66.78 \%$ tinggal di wilayah pedesaan. Dari segi psikologis, paling banyak pelaku UMKM melakukan pinjaman online dari dorongan diri sendiri dan mempunyai presepsi yang cukup, pengetahuan yang kurang serta sikap yang cukup.Dari faktor sosial paling banyak juga dimotivasi dari rekan kerja yang memakai pinjaman online. Pelaku penjual UMKM paling banyak berusia 36-45 tahun dengan pendapatan bersih setiap bulanya berada pada rentang kurang dari 5 juta.
\end{abstract}

Kata kunci : Financial Technology, Pinjaman Online, UMKM

\begin{abstract}
The use of technological advances in the financial sector is growing rapidly. Technological innovations present a more practical financial transaction process, one of which is applied to online loans. Online lending business practices connect lenders with online lenders. The disbursement of 22 trillion loans from 99 online loan companies registered with the OJK has made 9 million transactions to more than 3 million Indonesians. For this reason, it is necessary to analyze the factors that influence interest in using financial technology in the form of online loans. As one of Indonesia's financial drivers, Micro, Small and Medium Enterprises (MSMEs) play a role in transactions using online loan platforms. This study uses a quantitative approach by conducting an online survey of MSMEs to obtain primary data. The survey results show that $44.41 \%$ of SMEs use registered online loans, $18.75 \%$ use unregistered loans and $36.84 \%$ do not. The majority of businesses are SMEs in the culinary field with $58.88 \%$ of the main occupations, 50.99\% having high school education and $66.78 \%$ living in rural areas. From a psychological point of view, most MSME actors make online loans from self-indulgence and have sufficient perceptions, lack of knowledge and sufficient attitudes. From social factors, most of them are motivated by colleagues who use online loans. Most of the MSME sellers are aged 36-45 years with a monthly net income of less than 5 million.
\end{abstract}

Keywords : Financial Technology, Online Loans, MSMEs

\section{PENDAHULUAN}

Salah satu kemajuan dalam bidang keuangan saat ini adalah adanya adaptasi Fintech (Financial Technology). Menurut The National Digital Research Centre (NDRC), Fintech merupakan suatu inovasi pada sektor finansial. Tentunya, inovasi finansial ini mendapat sentuhan teknologi modern. Keberadaan Fintech dapat mendatangkan proses transaksi 
Prosiding The 1st National Conference on Applied Business, Education, \& Technology (NCABET)"

Unversitas Bina Bangsa 2021

DOI Article : 10.46306/ncabet.v1i1.2

keuangan yang lebih praktis dan aman (Chrismastianto, 2017). Menurut Clayton, Inovasi tersebut bertujuan untuk memperkenalkan kepraktisan, kemudahan akses, kenyamanan dan biaya yang ekonomis (Hadad, 2017). Latar belakang munculnya Fintech adalah ketika terjadi suatu masalah dalam masyarakat yang tidak dapat dilayani oleh industri keuangan dengan berbagai kendala, di antaranya adalah peraturan yang terlalu ketat di bank serta keterbatasan industri perbankan dalam melayani masyarakat di daerah tertentu. Jadi masyarakat yang jaraknya jauh dari akses perbankan cenderung belum bisa terlayani oleh perbankan. Hal ini mengakibatkan perkembangan ekonomi yang tidak merata.

Dengan adanya Fintech, masyarakat terpencil pun bisa menggunakan layanan keuangan yang berbasis teknologi, tanpa harus menempuh jarak yang jauh untuk mendapatkan layanan keuangan. Menurut data dari Findek Bank Dunia 2014, bahwa jumlah penduduk Indonesia yang telah memiliki rekening di lembaga keuangan formal hanya sekitar 36\%, sisanya yaitu $64 \%$ penduduk Indonesia tidak punya rekening dan akses terhadap lembaga keuangan formal atau sering disebut dengan istilah unbanked. Artinya lebih dari setengah masyarakat Indonesia belum terlayani oleh layanan keuangan seperti bank. Hal ini menjadi peluang bagi usaha yang bergerak di bidang keuangan untuk memanfaatkan teknologi. Misalnya seperti Investree yang merupakan perusahaan rintisan (startup) Fintech yang bergerak di bidang peer-to-peer lending yang mempertemukan orang dengan kebutuhan pendanaan (borrower) dan orang yang bersedia meminjamkan dananya (lender). Hal ini tentu saja memudahkan masyarakat untuk melakukan investasi ataupun mendapatkan pendanaan untuk usaha dengan lebih mudah tanpa harus bertemu langsung dengan menempuh jarak yang jauh. Manfaat lain yang didapatkan oleh lender adalah langsung mendapatkan bagi hasil yang dibayarkan oleh borrower tanpa beban biaya apapun.

Salah satu contoh platform jasa keuangan yang ditawarkan oleh pelaku usaha Fintech adalah pinjaman online. Praktik bisnis pinjaman online (P2P Lending) menghubungkan pemberi pinjaman dengan peminjam secara online. Sepanjang tahun 2018, penyaluran kredit yang dilakukan perusahaan bisnis finansial teknologi mencapai Rp. 22 triliun. Otoritas Jasa Keuangan selanjutnya dalam artikel ini disebut OJK mencatat bahwa angka tersebut berasal dari 99 perusahaan pinjaman online yang terdaftar di OJK, dan telah melakukan layanan lebih dari 9 juta transaksi pada lebih dari 3 juta masyarakat di seluruh Indonesia. Angka tersebut meningkat hampir delapan kali lipat jika dibandingkan dengan penyaluran kredit melalui bisnis finansial teknologi tahun 2017 yang tercatat Rp2,56 triliun. Dari Rp22 triliun kredit yang tersalurkan, rasio kredit macet (non- performing loan/NPL) tahun 2018 adalah sebesar 1,45\%, meningkat jika dibandingkan tahun 2017 yang berada pada level 0,99\% (Budiyanti, 2019). 
Pinjaman online (pinjol) illegal tidak ada matinya. Meski sering diberantas, masih saja ada yang muncul kembali. Terbaru Satgas Waspada Investasi (SWI) menemukan dan menutup 172 pinjol ilegal. Menurut Satgas Waspada Investasi, 172 pinjol ilegal ini beredar secara digital melalui penawaran lewat SMS, aplikasi gawai dan di internet yang berpotensi merugikan masyarakat karena bunga dan tenggat pinjaman yang tidak transparan, serta ancaman dan intimidasi dalam penagihan (Bestari, CNBC Indonesia, 2021)

Lembaga yang sangat berkontribusi pada perekonomian adalah Usaha Mikro Kecil dan Menengah (UMKM). Peningkatan akses dan jangkauan akses UMKM terhadap jasa keuangan sangat dibutuhkan untuk menghadapi persaingan dengan produk negara lain. Pengembangan UMKM membutuhkan kontribusi dan biaya lebih dari lembaga keuangan. Alternatif bank sebagai lembaga pembiayaan bagi UMKM memiliki keterbatasan informasi dan perlu adaptasi agar produk dan jasa bank sesuai dengan kebutuhan UMKM. Selain itu, diperlukan pula informasi mengenai prosedur dan persyaratan yang harus dipebuhi dalam mengakses pembiayaan. Pinjaman Online menjadi salah satu alternatif bagi UMKM untuk mendapatkan pembiayaan,

Keputusan masyarakat dalam penggunaan Financial Technology (Fintech) dalam Bentuk Pinjaman Online (Pinjol) sangat beragam sehingga peneliti tertarik untuk meneliti tentang Faktor-Faktor yang Mempengaruhi Keputusan Penggunaan Financial Technology (Fintech) dalam Bentuk Pinjaman Online (Pinjol) yang Terdaftar dan Tanpa Terdaftar di Otoritas Jasa Keuangan.

\section{METODE PENELITIAN}

Pendekatan yang digunakan pada penelitian ini yaitu kuantitatif, yakni dalam pengumpulan data, berlandaskan pada filsafat positifisme. Metode ini sebagai metode ilmiah karena telah memenuhi kaidah-kaidah ilmiah yang konkrit/empiris, obyektif, terukur, rasional, dan sistematis. Metode ini disebut juga dengan metode konfirmatif, karena metode ini cocok digunakan untuk pembuktian/konfirmatif. Metode ini disebut metode kuantitatif karena data penelitian berupa angka-angka dan analisis menggunakan statistik.

Tahapan penelitian kuantitatif berdasarkan yang dikemukakan Bryman (2008: 161) yaitu sebagai berikut:

\section{a. Variabel Penelitian dan Definisi Operasional}


Prosiding The 1st National Conference on Applied Business, Education, \& Technology (NCABET)",

Unversitas Bina Bangsa 2021

DOI Article : 10.46306/ncabet.v1il.2

\begin{tabular}{|l|l|l|l|}
\hline No & \multicolumn{1}{|c|}{ Variabel Penelitian } & \multicolumn{1}{|c|}{ Definisi Operasional dan Indikator } & Alat ukur \\
\hline 1 & Pengambilan Keputusan & Penggunaan pinjaman online, jenis UMKM & Kuisioner \\
\hline 2 & Faktor budaya & $\begin{array}{l}\text { a. Pekerjaan } \\
\text { b. Pendidikan } \\
\text { c. Wilayah Tinggal }\end{array}$ & Kuisioner \\
\hline 3 & Faktor sosial & $\begin{array}{l}\text { a. Kelompok Acuan } \\
\text { b. Keluarga } \\
\text { c. Peran dan status dalam masyarakat }\end{array}$ & Kuesioner \\
\hline 4 & Faktor pribadi & $\begin{array}{l}\text { a. Usia dan Tahap Siklus Hidup } \\
\text { b. Pekerjaan } \\
\text { c. Gaya Hidup } \\
\text { d. Kepribadian }\end{array}$ & Kuesioner \\
\hline 5 & Faktor psikologis & $\begin{array}{l}\text { a. Motivasi } \\
\text { b. Persepsi } \\
\text { c. Pembelajaran } \\
\text { d. Keyakinan dan Sikap }\end{array}$ & Kuesioner \\
\hline
\end{tabular}

\section{b. Populasi dan Sampel Penelitian}

Populasi dalam penelitian adalah seluruh pelaku UMKM Indonesia pernah menggunakan fintech berupa pinjaman online. Terdapat 304 sample yang berhasil penulis kumpulkan.

\section{c. Teknik Pengumpulan Data}

Pengambilan data menggunakan data primer. Untuk bisa mendapatkan data dari responden, angket atau kuisioner biasanya didistribusikan langsung kepada para responden. Namun, seiring perkembangan teknologi, media online yang semakin berkembang pun mulai banyak dimanfaatkan untuk survei online. Survei online adalah sebutan bagi metode survei yang memanfaatkan media online untuk mengumpulkan data dari para responden, dengan mendistribusikan angket atau kuisioner secara online.

\section{HASIL DAN PEMBAHASAN}

Tabel 2 Distribusi Penggunaan Pinjol pada UMKM

\begin{tabular}{|r|l|r|r|}
\hline \multicolumn{1}{|c|}{ No } & \multicolumn{1}{|c|}{ Penggunaan Pinjol } & Jumlah & \multicolumn{1}{c|}{ \% } \\
\hline 1 & Menggunakan Pinjol Terdaftar & 135 & 44,41 \\
\hline 2 & Menggunakan Pinjol Tidak Terdaftar & 57 & 18,75 \\
\hline
\end{tabular}




\begin{tabular}{|r|l|r|r|}
\hline \multicolumn{1}{|c|}{ No } & \multicolumn{1}{|c|}{ Penggunaan Pinjol } & Jumlah & \multicolumn{1}{c|}{$\%$} \\
\hline 3 & Tidak Menggunakan & 112 & 36,84 \\
\hline & Total & $\mathbf{3 0 4}$ & $\mathbf{1 0 0}$ \\
\hline
\end{tabular}

\section{Sumber: Data Primer, 2021}

Berdasarkan Tabel 2 diketahui yang memiki presentase tertinggi penggunaan pinjol pada UMKM adalah kategori menggunakan pinjol terdaftar sebesar 44,41\% atau sebesar 135 UMKM.

Tabel 3 Distribusi Jenis UMKM

\begin{tabular}{|l|l|r|r|}
\hline \multicolumn{1}{|c|}{ No } & \multicolumn{1}{|c|}{ Jenis UMKM } & Jumlah & \multicolumn{1}{c|}{$\%$} \\
\hline 1 & Usaha Kuliner & 88 & 28,95 \\
\hline 2 & Usaha Fashion & 52 & 17,11 \\
\hline 3 & Usaha Bidang Teknologi & 11 & 3,62 \\
\hline 4 & Usaha kosmetik & 21 & 6,91 \\
\hline 5 & Usaha Bidang Otomotif & 62 & 20,39 \\
\hline 6 & Usaha Cendera Mata & 40 & 13,16 \\
\hline 7 & Usaha Agrobisnis & 30 & 9,87 \\
\hline & Total & $\mathbf{3 0 4}$ & $\mathbf{1 0 0}$ \\
\hline
\end{tabular}

Sumber: Data Primer, 2021

Berdasarkan Tabel 3 diketahui yang memiki presentase tertinggi Jenis UMKM adalah kategori Usaha Kuliner sebesar 28,95\% atau sebesar 88 UMKM.

Tabel 4 Distribusi factor budaya pada UMKM

\begin{tabular}{|r|l|r|r|}
\hline \multicolumn{1}{|c|}{ No } & \multicolumn{1}{|c|}{ Juktor Budaya } & & \multicolumn{1}{c|}{ \% } \\
\hline 1 & Pekerjaan & 179 & 58,88 \\
\hline & Usaha Pekerjaan Utama & 125 & 41,12 \\
\hline & Usaha Pekerjaan Sampingan & $\mathbf{3 0 4}$ & $\mathbf{1 0 0}$ \\
\hline & Total & & \\
\hline & Pendidikan & 21 & 6,91 \\
\hline & Tidak Sekolah & 17 & 5,59 \\
\hline & SD & 32 & 10,53 \\
\hline & SMP & 155 & 50,99 \\
\hline & SMA & 72 & 23,68 \\
\hline & Sarjana & 5 & 1,64 \\
\hline
\end{tabular}


Prosiding The 1st National Conference on Applied Business, Education, \& Technology (NCABET)",

Unversitas Bina Bangsa 2021

DOI Article : $10.46306 /$ ncabet.v1i1.2

\begin{tabular}{|r|l|r|r|}
\hline No & \multicolumn{1}{|c|}{ Faktor Budaya } & Jumlah & \multicolumn{1}{|c|}{$\%$} \\
\hline & Doktor & 2 & 0,66 \\
\hline 3 & Total & $\mathbf{3 0 4}$ & $\mathbf{1 0 0}$ \\
\hline & Wilayah Tinggal & & \\
\hline & Pedesaan & 203 & 66,78 \\
\hline & Perkotaan & 101 & 33,22 \\
\hline & Total & $\mathbf{3 0 4}$ & $\mathbf{1 0 0}$ \\
\hline
\end{tabular}

\section{Sumber: Data Primer, 2021}

Berdasarkan Tabel 4 diketahui yang memiki presentase tertinggi factor budaya dalam kategori pekerjaan adalah usaha pekerjaan utama sebesar 58,88\% atau 179 pelaku UMKM. Kategori pendidikan presentase tertinggi adalah SMA sebesar 50,99\% atau 155 pelaku UMKM. Dan kategori pada wilayah tinggal presentase tertinggi adalah di daerah pedesaan 66,78\% atau 203 pelaku UMKM.

Tabel 5 Distribusi faktor psikologis pada UMKM

\begin{tabular}{|r|l|r|r|}
\hline \multicolumn{1}{|c|}{ No } & \multicolumn{1}{|c|}{ Faktor Psikologis } & \multicolumn{1}{c|}{ Jumlah } & \\
\hline 1 & Motivasi & 213 & 70,07 \\
\hline & Dorongan dari Diri Sendiri & 91 & 29,93 \\
\hline & Dorongan dari Orang lain & $\mathbf{3 0 4}$ & $\mathbf{1 0 0}$ \\
\hline 2 & Total & & \\
\hline & Persepsi & 134 & 44,08 \\
\hline & Cukup & 156 & 51,32 \\
\hline & Kurang & 14 & 4,61 \\
\hline & Total & $\mathbf{3 0 4}$ & $\mathbf{1 0 0}$ \\
\hline 3 & Pengetahuan & 113 & 37,17 \\
\hline & Baik & 67 & 22,04 \\
\hline & Cukup & 124 & 40,79 \\
\hline & Kurang & $\mathbf{3 0 4}$ & $\mathbf{1 0 0}$ \\
\hline & Total & & 8,22 \\
\hline & Sikap & 127 & 41,78 \\
\hline & Baik & & 50,00 \\
\hline & Kukup & & \\
\hline
\end{tabular}




\begin{tabular}{|c|l|r|r|}
\hline No & \multicolumn{1}{|c|}{ Faktor Psikologis } & Jumlah & \multicolumn{1}{c|}{$\%$} \\
\hline & Total & 304 & 100 \\
\hline
\end{tabular}

\section{Sumber: Data Primer, 2021}

Berdasarkan Tabel 5 diketahui yang memiki presentase tertinggi factor psikologis dalam kategori motivasi adalah dorongan dari diri sendiri sebesar 70,07\% atau 213 pelaku UMKM. Namun dalam kategori persepsi presentase tertinggi adalah cukup yaitu sebesar 51,32\% atau 156 pelaku UMKM. Kategori pada pengetahuan presentase tertinggi adalah kurang yaitu sebesar 40,79\% atau 124pelaku UMKM, dan kategori pada sikap presentase tertinggi adalah cukup yaitu sebesar 50,00\% atau 152 pelaku UMKM.

Tabel 6 Distribusi faktor sosial pada UMKM

\begin{tabular}{|r|l|r|r|}
\hline \multicolumn{1}{|c|}{ No } & \multicolumn{1}{|c|}{ Jaktor Sosial } & \multicolumn{1}{|c|}{ Jumlah } & \multicolumn{1}{|c|}{} \\
\hline 1 & Rekan kerja yang memakai pinjol & 219 & 72,04 \\
\hline & Ya & 85 & 27,96 \\
\hline & Tidak & $\mathbf{3 0 4}$ & $\mathbf{1 0 0}$ \\
\hline 2 & Total & 158 & 51,97 \\
\hline & Ya & 146 & 48,03 \\
\hline & Tidak & $\mathbf{3 0 4}$ & $\mathbf{1 0 0}$ \\
\hline 3 & Total & & 28,95 \\
\hline & Ya & 88 & 71,05 \\
\hline & Tidak & 216 & $\mathbf{1 0 0}$ \\
\hline & Total & $\mathbf{3 0 4}$ & \\
\hline
\end{tabular}

\section{Sumber: Data Primer, 2021}

Berdasarkan Tabel 6 diketahui yang memiki presentase tertinggi factor social dalam kategori Rekan kerja yang memakai pinjol sebesar 72,04\% atau 219 pelaku UMKM. Namun dalam kategori Keluarga yang memakai pinjol sebesar 51,97\% atau 158 pelaku UMKM, dan kategori pada Lingkungan Masyarakat memakai pinjol sebesar 71,05\% atau 216pelaku UMKM.

Tabel 7 Distribusi faktor pribadi pada UMKM 
Prosiding The 1st National Conference on Applied Business, Education, \& Technology (NCABET)" Unversitas Bina Bangsa 2021

DOI Article : 10.46306/ncabet.v1i1.2

\begin{tabular}{|c|c|c|c|}
\hline No & Faktor Pribadi & Jumlah & $\%$ \\
\hline \multirow[t]{8}{*}{1} & Usia (Depkess RI) & & \\
\hline & Remaja Awal 12-16 Tahun & 0 & 0,00 \\
\hline & Reamaja Akhir 17- 25 Tahun & 47 & 15,46 \\
\hline & Dewasa Awal 26-35 Tahun & 103 & 33,88 \\
\hline & Dewasa Akhir 36-45 Tahun & 121 & 39,80 \\
\hline & Lansia Awal 46-55 Tahun & 33 & 10,86 \\
\hline & Lansia Akhir > 56 Tahun & 0 & 0,00 \\
\hline & Total & 304 & 100 \\
\hline \multirow[t]{13}{*}{2} & Penghasilan (Pendapatan Bersih/Bulan) & & \\
\hline & $<5$ Juta & 134 & 44,08 \\
\hline & 5- 10 Juta & 56 & 18,42 \\
\hline & 11- 15 Juta & 89 & 29,28 \\
\hline & $16-20$ Juta & 3 & 0,99 \\
\hline & 21- 25 Juta & 6 & 1,97 \\
\hline & 26- 30 Juta & 6 & 1,97 \\
\hline & 31-35 Juta & 2 & 0,66 \\
\hline & 36- 40 Juta & 1 & 0,33 \\
\hline & 41-45 Juta & 1 & 0,33 \\
\hline & 46-50 Juta & 2 & 0,66 \\
\hline & $>50$ Juta & 4 & 1,32 \\
\hline & Total & 304 & 100 \\
\hline \multirow[t]{10}{*}{3} & Gaya Hidup (Pengeluaran) & & \\
\hline & $<5$ Juta & 88 & 28,95 \\
\hline & 5- 10 Juta & 132 & 43,42 \\
\hline & 11- 15 Juta & 65 & 21,38 \\
\hline & $16-20$ Juta & 3 & 0,99 \\
\hline & 21- 25 Juta & 2 & 0,66 \\
\hline & 26- 30 Juta & 3 & 0,99 \\
\hline & 31-35 Juta & 2 & 0,66 \\
\hline & 36- 40 Juta & 1 & 0,33 \\
\hline & 41-45 Juta & 1 & 0,33 \\
\hline
\end{tabular}




\begin{tabular}{|r|c|r|r|}
\hline No & \multicolumn{1}{|c|}{ Faktor Pribadi } & Jumlah & \multicolumn{1}{|c|}{$\%$} \\
\hline & 46-50 Juta & 2 & 0,66 \\
\hline & $>50$ Juta & 5 & 1,64 \\
\hline & Total & $\mathbf{3 0 4}$ & $\mathbf{1 0 0}$ \\
\hline
\end{tabular}

\section{Sumber: Data Primer, 2021}

Berdasarkan Tabel 7 diketahui yang memiki presentase tertinggi factor pribadi dalam kategori usia adalah Dewasa Akhir 36-45 Tahun sebesar 39,80\% atau 121 pelaku UMKM. Namun dalam kategori pendidikan presentase tertinggi Penghasilan (Pendapatan Bersih/Bulan) adalah < 5 Juta sebesar 44,08\% atau 134 pelaku UMKM, dan kategori pada Gaya Hidup (Pengeluaran) presentase tertinggi adalah 5- 10 Juta sebesar 43,42\% atau 132 pelaku UMKM.

\section{KESIMPULAN}

1. Berdasarkan Distribusi Penggunaan Pinjol pada UMKM yang memiki presentase tertinggi penggunaan pinjol pada UMKM adalah kategori menggunakan pinjol terdaftar sebesar $44,41 \%$ atau sebesar 135 UMKM

2. Berdasarkan Distribusi Jenis UMKM yang memiki presentase tertinggi Jenis UMKM adalah kategori Usaha Kuliner sebesar 28,95\% atau sebesar 88 UMKM

3. Berdasarkan Distribusi faktor budaya pada pelaku UMKM yang memiki presentase tertinggi faktor budaya dalam kategori pekerjaan adalah usaha pekerjaan utama sebesar 58,88\% atau 179 pelaku UMKM. Kategori pendidikan presentase tertinggi adalah SMA sebesar 50,99\% atau 155 pelaku UMKM. Dan kategori pada wilayah tinggal presentase tertinggi adalah di daerah pedesaan $66,78 \%$ atau 203 pelaku UMKM

4. Berdasarkan Distribusi faktor psikologis pada UMKM yang memiki presentase tertinggi factor psikologis dalam kategori motivasi adalah dorongan dari diri sendiri sebesar 70,07\% atau 213 pelaku UMKM. Namun dalam kategori persepsi presentase tertinggi adalah cukup yaitu sebesar 51,32\% atau 156 pelaku UMKM. Kategori pada pengetahuan presentase tertinggi adalah kurang yaitu sebesar 40,79\% atau 124 pelaku UMKM. Kategori pada sikap presentase tertinggi adalah cukup yaitu sebesar 50,00\% atau 152pelaku UMKM

5. Berdasarkan Distribusi faktor social pada UMKM yang memiki presentase tertinggi factor social dalam kategori Rekan kerja yang memakai pinjol sebesar 72,04\% atau 219 pelaku UMKM. Namun dalam kategori Keluarga yang memakai pinjol sebesar 51,97\% atau 158 pelaku UMKM. Kategori pada Lingkungan Masyarakat memakai pinjol sebesar 71,05\% atau 216pelaku UMKM. 
Prosiding The 1st National Conference on Applied Business, Education, \& Technology (NCABET)"

Unversitas Bina Bangsa 2021

DOI Article : 10.46306/ncabet.v1i1.2

6. Berdasarkan Distribusi faktor pribadi pada UMKM yang memiki presentase tertinggi factor pribadi dalam kategori usia adalah Dewasa Akhir 36-45 Tahun sebesar 39,80\% atau 121 pelaku UMKM. Namun dalam kategori pendidikan presentase tertinggi Penghasilan (Pendapatan Bersih/Bulan) adalah < 5 Juta sebesar 44,08\% atau 134 pelaku UMKM. Kategori pada Gaya Hidup (Pengeluaran) presentase tertinggi adalah 5- 10 Juta sebesar $43,42 \%$ atau 132 pelaku UMKM.

\section{UCAPAN TERIMAKASIH}

Ucapan terimakasih kepada pihak-pihak yang membantu penelitian, dari KOPITU, STMA Trisakti dan para responden yang berasal dari UMKM di Indonesia.

\section{DAFTAR PUSTAKA}

Bryman, A. (2008). Sosial Research Methods, Third Edition, New York: Oxford University Press Inc.

Byrne, B. M. (2010). Structural equation modeling with AMOS: basic concepts, applications, and programming (multivariate applications series). New York: Taylor \& Francis Group, $396,7384$.

Carney, M. (2016).Enabling the fintech transformation: Revolution, Restoration, or Reformation. BoE Speech.

Chrismastianto, Imanuel Aditya, W. (2017). Analisis Swot Implementasi Teknologi Finansial Terhadap Kualitas Layanan Perbankan di Indonesia. Jurnal Ekonomi dan Bisnis: Fakultas Ilmu Pendidikan Universitas Pelita Harapan Tangerang, Vol. 20, (No.1, April 2017), p. 137.

Hansson, Sven Ove. 2005. Decision Theory : A Brief Introduction. Stockholm: Royal Institute of Technology

Hadad, Muliaman D. 2017.Financial Techonology (Fintech) di Indonesia. Jakarta: Otoritas Jasa Keuangan

Jonathan, S., Narimawati, U. (2015).Membuat Skripsi, Tesis, dan Disertasi dengan Partial Least Square SEM (PLS - SEM). Yogyakarta: Penerbit Andi.

Kotler, Philip dan Kevin Lene,Keller. 2007. Manajemen Pemasaran. Edisi 12.Jilid 2. Jakarta: PT indeks kelompok Gramedia.

Kotler, Philip dan Gary Amstrong, 2006, Prinsip-Prinsip Pemasaran, Jilid 1, Edisi 12, Terjemahan: Bob Sabran, M.M, Jakarta: Erlangga

Latan, H (2013). Structural Equation Modeling. Bandung: Alfabeta 
Santoso, Singgih, 2011. Structural Equation Modeling (SEM) Konsep dan Aplikasi dengan AMOS 18.Jakarta : Penerbit PT Elex Media Komputindo

Schiffman \& Kanuk. 2004. Perilaku Konsumen (edisi 7). Jakarta: Prentice Hall.

Sugiyono. 2013. Metode Penelitian Pendidikan Pendekatan Kuantitatif, Kualitatif, dan R\&D. Bandung: Alfabeta.

Peraturan Bank Indonesia Nomor 19/12/PBI/2017 Tentang Penyelenggaraan Teknologi Finansial. Indonesia

Peraturan Otoritas Jasa Keuangan Republik Indonesia Nomor 13/POJK.02/2018 Mengenai Inovasi Keuangan Digital di Sektor Jasa Keuangan. Indonesia.

Bestari N. P. CNBC Indonesia, 2021. https://www.cnbcindonesia.com/tech/20210714113635 -37-260740/daftar-172-pinjol-ilegal-yang-ditutup-ojk-waspadalah 